\title{
Cross-modality transfer effects in conditioning-enhanced neophobia in chicks (Gallus domesticus): Evidence for the separability of novelty from specific stimulus characteristics
}

\author{
JOSEPH J. FRANCHINA and ANTOINETTE B. DYER \\ Virginia Polytechnic Institute and State University, Blacksburg, Virginia
}

\begin{abstract}
In this study, we investigated the separability of novelty from specific stimulus characteristics (e.g., color or taste quality) in the transfer of aversion effects. Ninety-six chicks (Gallus domesticus) received a novel visual (red water) or taste (3.0\% vinegar) CS paired with an injection of lithium chloride or saline. The chicks were then tested for aversion to the CS or for conditioningenhanced neophobia in response to a different novel visual cue (green water) or taste cue (1.0\% saline). Aversions to the CSs were reliable and similar to each other. Reliable evidence of conditioning-enhanced neophobia occurred with respect to each test stimulus, irrespective of the type of CS, but conditioning with the vinegar CS produced reliably greater enhancement of neophobia than did conditioning with red water. For each CS, postconditioning neophobia was more persistent in testing with saline than with green water. The results for postconditioning neophobia suggested that novelty is a general stimulus property that is separable from specific stimulus characteristics.
\end{abstract}

Ingestional neophobia refers to the finding that omnivores, such as rats, exhibit reduced intake of food or drink when these ingesta are novel in taste or appearance or when familiar ingesta appear in a novel environment or container (e.g., Braveman, 1978; Bravemen \& Jarvis, 1978; Mitchell, Kirschbaum, \& Perry, 1975). Neophobia is presumed to reflect the aversive properties of novelty (Domjan, 1976).

According to Kalat (1974) and others (Mitchell et al., 1975; Mitchell, Winter, \& Moffitt, 1980), novelty refers to the discrepancy between a current stimulus, in this case flavor, and previously experienced stimuli of the same class. In taste aversion and neophobia, novelty typically reflects the discrepancy between present and previously experienced taste characteristics of an edible, although other dimensions of the edible, such as temperature, texture, and appearance, may contribute to the novelty condition.

Braveman and Jarvis (1978) have proposed that novelty is a property common to newly presented stimuli but separable from the particular characteristics of the stimuli. For example, sucrose and saline solutions have the specific

This paper was originally presented at the meeting of the American Association for the Advancement of Science, Philadelphia, 1986. Gratitude is expressed to $K$. L. Slank for critically reading the manuscript. Reprint requests should be addressed to Joseph J. Franchina, Department of Psychology, VPI \& SU, Blacksburg, VA 24061. A. B. Dyer is now in the Department of Psychology at Davidson College, Davidson, NC 28036 taste characteristics of sweetness and saltiness. However, at their first presentation (e.g., to the rat), these flavors share the property of novelty, insofar as they differ distinctively from previously experienced drinking solutions. Evidence for novelty's being a general stimulus characteristic is that preexposure to one (or several) distinctive novel flavor(s) reduces the magnitude of neophobia and of conditioning-enhanced neophobia in response to other novel flavors (Braveman \& Jarvis, 1978; Franchina \& Gilley, 1986; Miller \& Holzman, 1981). In addition, preexposure to novel feeding environments reduces neophobia in response to a novel flavor and vice versa (Braveman, 1978, Experiments 2 and 3).

According to Braveman and Jarvis (1978), preexposures reduce neophobia by reducing the aversiveness of novelty and by providing information about specific characteristics of a stimulus, such as flavor intensity. When preexposure effects occur between different stimuli within the same modality (e.g., between salt- and sweet-tasting solutions) or between stimuli of different modalities (e.g., between visual and taste stimuli), the basis for such effects is not likely to be a generalization of specific stimulus characteristics of the ingesta (e.g., see Braveman, 1978; Miller \& Holzman, 1981; Mitchell et al., 1980). Rather, generalization may more likely occur because of the property of novelty, common to newly presented stimuli that may differ in specific characteristics (e.g., taste).

The evidence for the cross-modality transfer of preexposure effects has come mainly from studies of the in- 
fluence of preexposure to contextual stimuli (home-cage environment) or feeding-related stimuli (food cup) on neophobia in response to taste cues (e.g., Braveman, 1978; Mitchell et al., 1980). Thus, transfer has occurred between noningestional, contextual stimuli and the specific, ingestional stimuli of taste. Since food selection may be based on visual and taste cues of ingesta (e.g., see Galef \& Dalrymple, 1981; Galef \& Osborne, 1978; Wilcoxon, 1977), these data raise the question of whether crossmodality effects would occur between the stimulus characteristics of a food. Specifically, would experience of the novel appearance of a food influence responding to a novel-tasting food and vice versa? Furthermore, evidence for the separability of novelty from specific stimulus characteristics (e.g., taste) has frequently employed preexposure procedures that lessen the influence of novelty on the phenomenon of neophobia. A complementary approach to this would be to investigate cross-modality effects in which novelty enhances the phenomenon of interest.

In conditioning-enhanced neophobia (CEN), conditioned aversions to a distinctive novel flavor, such as sucrose, occur with respect to another novel flavor, such as casein hydrolysate, and augment the demonstration of neophobia in response to the latter. Presumably, aversion to casein occurs because sucrose and casein are discrepant from previously ingested flavors and thus share the property of novelty, or because sucrose and casein have similar taste characteristics within the same stimulus class-that is, flavors (Domjan, 1980; Franchina \& Gilley, 1986). In terms of CEN, evidence for novelty as separable from specific stimulus characteristics would be that conditioned aversions to a novel stimulus in one modality transfer to a novel stimulus in another modality. For example, conditioned aversions to a novel taste CS, such as vinegar, should augment the demonstration of neophobia in response to a novel visual cue, such as greencolored water.

\section{METHOD}

\section{Subjects}

Ninety-six White Leghorn chicks (Gallus domesticus) were hatched from eggs from the Poultry Research Center at Virginia Polytechnic Institute and State University. Upon arrival at the laboratory, the eggs were placed in a Humidare Incubator (model no. 50) at $37.6^{\circ} \pm 1^{\circ} \mathrm{C}$ and $70.0 \% \pm 5.0 \%$ relative humidity. After 18 days, the eggs were transferred to a Leahy Hatcher (model no. 416), where they remained until the chicks hatched. The hatcher temperature was $37.2^{\circ} \mathrm{C}$; relative humidity was $75.0 \%+5.0 \%$.

Approximately $12 \mathrm{~h}$ posthatch, the chicks were housed $(n=4)$ in wire mesh double cages $(41.8 \times 25.0 \times 17.9 \mathrm{~cm})$. The cage floors were lined with crinoline to prevent leg and foot injury. At 21 days of age (Day 1), the chicks were housed singly in cages $(25.0 \times 17.9 \times 17.9 \mathrm{~cm})$ for the experiment. The experimental room illumination was $240 \mathrm{~lx}$. Light onset occurred at $0600 \mathrm{~h}$; light offset, at $2000 \mathrm{~h}$. Food and water were always available, except as noted. Food was always presented in a clear glass jar, $4.2 \mathrm{~cm}$ in diameter and $4.5 \mathrm{~cm}$ deep, in the left front corner of the cage. Water was presented in a highly similar jar in the right front corner of the cage.

\section{Design and Procedure}

On Day 1, the chicks were randomly assigned to a $2 \times 2 \times 3$ de$\operatorname{sign}(n=8)$. There were two CSs (red-colored water or clear $3.0 \%$ vinegar), two injection conditions (a CS paired with a lithium chloride injection or with a saline injection), and three test stimuli (the original CS, green-colored water, or clear $1.0 \%$ saline).

The experiment lasted for 12 days: three days for acclimating the chicks to the home cage and water deprivation (Days 1-3), 2 training days (Days 4-5), 4 recovery days (Days 6-9), and 3 test days (Days 10-12). Beginning on Day 2, the chicks received access to tap water in Ritcher-type drinking tubes for $10 \mathrm{~min}$ at $0830 \mathrm{~h}$ and for $30 \mathrm{~min}$ at $1530 \mathrm{~h}$. Hereafter, Richter-type tubes were used for all fluid access.

On Days 4 and 5, at $0830 \mathrm{~h}$, food was removed from each cage. On Day 4, each chick received $10 \mathrm{~min}$ of access to a CS, which was followed, within $5 \mathrm{~min}$, by an i.p. injection at $2.0 \%$ body weight. For each CS, half of the chicks (conditioning group) were injected with $0.4 \mathrm{M}$ lithium chloride ( $\mathrm{LiCl}$ ); the other half (control group), with $0.9 \%$ isotonic saline. On Day 5 , all chicks received $10 \mathrm{~min}$ of access to tap water, followed by a saline injection for conditioning groups and $\mathrm{aiCl}$ injection for controls. The latter procedure controlled for the influence of the ingestion-toxin contingency on performance in testing (hence, ITC controls). Food was returned to the cage at $1530 \mathrm{~h}$; each chick received $30 \mathrm{~min}$ of access to tap water.

On recovery Days 6 and 7, food and tap water were available ad lib. On recovery Days 8 and 9, the chicks had access to tap water for $10 \mathrm{~min}$ at $0830 \mathrm{~h}$ and for $30 \mathrm{~min}$ at $1530 \mathrm{~h}$. Food was always available.

Testing occurred on Days 10-12, one trial/day. On each day at $0830 \mathrm{~h}$, food was removed from each cage. Chicks received $10 \mathrm{~min}$ of access to their original CS (red water or clear $3.0 \%$ vinegar) to test for aversion effects, or $10 \mathrm{~min}$ of access to novel green water or to clear $1.0 \%$ saline to test for CEN. The measure of performance was the amount drunk, calculated to the nearest $100 \mathrm{mg}$ as the difference between pre- and posttest tube weights. Food was returned to the cages after the end of daily testing. Thirty minutes of access to tap water occurred at $1530 \mathrm{~h}$ daily.

The flavor solutions were made with Heinz distilled white vinegar and reagent grade sodium chloride (Fisher brand), mixed, respectively, with distilled water at room temperature. The colored solutions were made with McCormick's food coloring: $1.0 \mathrm{cc}$ of red coloring and $99.0 \mathrm{cc}$ of distilled water; $0.5 \mathrm{cc}$ of green coloring and $99.5 \mathrm{cc}$ of water. All fluids were always presented at room temperature. Solutions were mixed approximately $18 \mathrm{~h}$ before presentation.

\section{RESULTS}

\section{Injection and Recovery-Day Intakes}

On the first injection day, mean intake (in grams) of vinegar (10.5) was below that of red water $(13.0)[F(1,84)$ $=4.46, p<.05]$. To assess recovery of ingestion following toxicosis but before testing, tap water intakes were measured at $0830 \mathrm{~h}$ on Day 9. An ANOVA revealed no reliable differences in water intake for any comparisons $(p s>.20)$. Hence, subsequent differences in aversion to the CS and in CEN cannot be attributed to the influence of toxicosis per se on ingestion, nor to the suppression of ingestion by the establishment of aversive properties in the home cage context. 


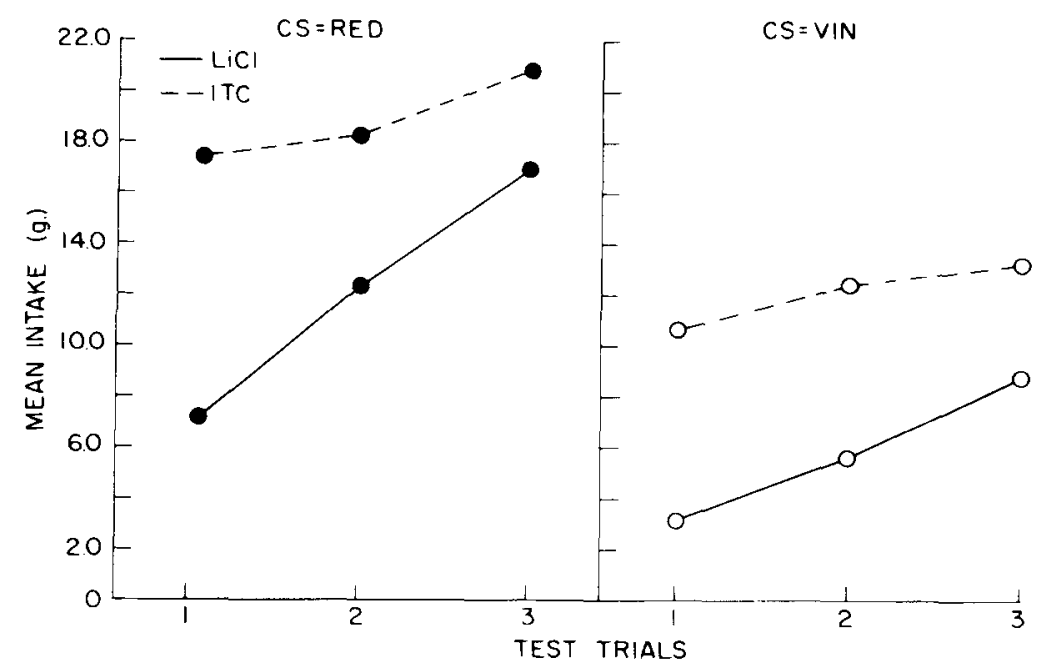

Figure 1. Mean intake (in grams) of red water (RED) and vinegar (VIN) on Test Trials 1 -3 for conditioning groups (LiCl) and ingestion-toxin controls (TTC) that were tested on the CS.

\section{Aversion Testing}

Figure 1 shows mean intake (in grams) of red water and vinegar CSs on Test Trials 1-3. For each CS, intake by the conditioning $(\mathrm{LiCl})$ groups was below that of the ingestion toxin controls (ITC groups). Intake of the vinegar CS was below that of the red water CS in each injection condition. An ANOVA of all these data revealed reliable effects for injection condition, type of CS, and test trials $[F \mathrm{~s}(1,28,1,28$, and 2,56$)=5.59,5.65$, and 11.02 , respectively, ps $<.05]$. Because the reliable effect of the CS may reflect differences in baseline intakes between red water and vinegar, the data of Figure 1 were converted to percentage scores. The intake on each trial for each subject in a $\mathrm{CS}-\mathrm{LiCl}$ group was divided by the mean intake of its appropriate ITC group, all times 100 (Franchina \& Dyer, 1985). An ANOVA of the percentage intake data yielded no reliable effect for the CS or for CS $X$ test trials $(p s>.20)$, suggesting that the magnitude of aversion was similar across CSs.

\section{CEN Testing}

Figure 2 shows mean intake (in grams) of green water and saline $(\mathrm{NaCl})$ over test trials. Evidence of CEN occurred for each test stimulus: intakes for the $\mathrm{LiCl}$ groups were below those for the ITC groups. For each test stimulus, CEN was greater following conditioning with vine-

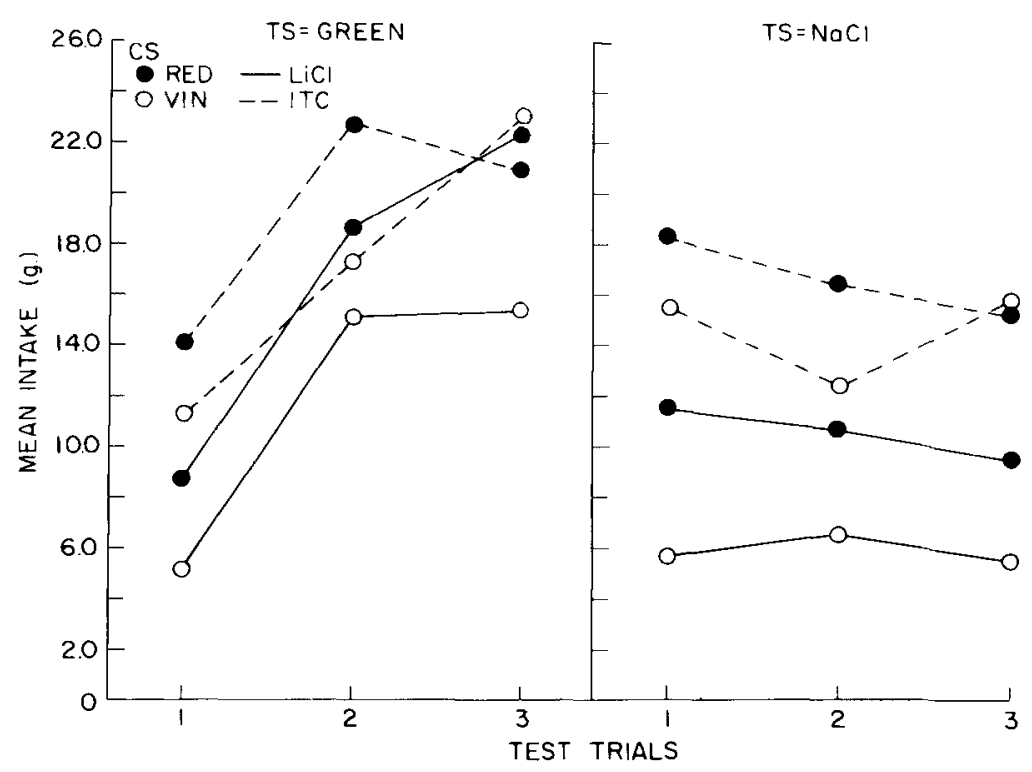

Figure 2. Mean intake (in grams) of green water and saline ( $\mathrm{NaCl}$ ) on neophobia Test Trials 1-3 for groups that were previously conditioned with red water (RED) or vinegar (VIN) CSs, or given ingestion-toxin control (ITC) procedures. 
gar than with red water. CEN was more persistent for $\mathrm{NaCl}$ than for green water, irrespective of the CS.

An ANOVA of these data revealed reliable effects for injection condition, type of CS, and test stimulus $\times$ test trials $\left[F_{\mathrm{s}}(1,56,1,56\right.$, and 2,112$)=13.56,4.62$, and $18.69, p s<.01, .05$, and .01 , respectively]. No other factors were reliable ( $p$ s $>.10$ ). An ANOVA of the data for each test stimulus yielded a reliable trials effect for testing with green water $[F(2,56)=20.61, p<.01]$, but not for testing with $\mathrm{NaCl}(F<1)$. A trial-by-trial ANOVA across test stimuli revealed no reliable effect for test stimulus on Trial $1(F<1)$ and a reliable effect on Trials 2 and $3[F \mathrm{~S}(1,56)=10.52$ and $23.87, p<.01]$.

\section{DISCUSSION}

In this experiment, conditioning-enhanced neophobia occurred in response to novel test cues of green-colored water or clear saline, whether these cues were in the same stimulus class as the CS or from a different modality than the CS. Specifically, conditioning-enhanced neophobia $\alpha$ curred in response to novel green-colored water and to novel $1.0 \%$ clear saline following conditioning with a CS of red-colored water or clear $3.0 \%$ vinegar. In neophobia testing, the presentation of novel visual or taste cues presumably curtails ingestion because novelty has aversive properties that elicit avoidance of the novel ingesta (Domjan, 1976). Avoidance (reduced ingestion) is augmented for the conditioning group, presumably because the CS-toxin pairing establishes an aversion to the novel CS, which generalizes to test cues on the basis of the novelty shared by the CS and the test stimuli, irrespective of their specific characteristics, such as color or taste (Braveman \& Jarvis, 1978).

Evidence of cross-modality transfer in conditioningenhanced neophobia supports the view of novelty as a nonspecific property of stimuli. Finding cross-modality effects required that the association formed by the CS-toxin pairing survived alteration of stimulus characteristics from $\mathrm{CS}$ training to neophobia testing. Operationally speaking, testing across modalities yielded greater alteration of the stimuli that had accompanied the toxin for the conditioning groups than for the ITC groups. Briefly, conditioning with red water $C S$ and testing with clear saline, as well as conditioning with a clear vinegar CS and testing with green water, involved an apparent change in visual and taste stimuli for $\mathrm{CS}-\mathrm{LiCl}$ groups. The ITC groups received a clear water-toxin pairing. For them, neophobia testing involved an apparent change in visual cues in testing with green-colored water and a change in taste cues in testing with clear saline. According to a traditional view of stimulus generalization, alteration of the previously conditioned stimulus should yield a decrement in associative strength (Deese \& Hulse, 1958, p. 171). In tasteaversion performance, this decrement should have been greater for conditioning groups and should have militated against finding a reliable difference between these groups and the ITC groups.

Admittedly, cross-modality generalization may have occurred for the conditioning groups on the basis of some unidentified stimulus dimension of vision and taste shared by the CS and test cues. Identification of that dimension is not obvious to us. Furthermore, the present procedures were adopted to ensure that the background cues from the home environment, the location and appearance of the drinking tubes, and the characteristics of the fluids (such as temperature and texture) would remain invariant between the conditioning and the ITC groups across training and testing, in order to preclude a differential basis for generalization in these groups. Since conditioningenhanced neophobia occurred for the conditioning groups, which received a greater change in specific stimulus characteristics than did the ITC groups, and since attribution of this effect to an unidentified stimulus dimension seems gratuitous, it seems plausible to attribute the cross-modality effects to generalization based on novelty, which is separable from specific stimulus characteristics.

Finally, the results for postconditioning neophobia did suggest evidence for the role of specific stimulus characteristics, taste cues being more influential than visual cues were. For example, conditioning with vinegar yielded reliably greater postconditioning neophobia than did conditioning with red water, although the percentage intake data exhibited similar reliable aversion effects across the CSs. These data suggest that postconditioning neophobia may depend on specific CS characteristics but not necessarily on the manifest strength of the original aversion. Furthermore, conditioning-enhanced neophobia was more persistent in testing with novel saline than with greencolored water, irrespective of CS characteristics. These data suggest that postconditioning neophobia may depend upon the associability of taste and toxicosis, even in avian species, which have highly developed visual systems. Clarke, Westbrook, and Irwin (1979) have argued that degree of anatomical development may not necessarily determine which stimuli acquire aversion-conditioning properties and which do not.

In summary, the present results for postconditioning neophobia coincide with previous studies of fluid intake that have demonstrated stronger taste aversion than visual aversions in pigeons (Clarke et al., 1979) and chickens (Gaston, 1977; Gillette, Martin, \& Bellingham, 1980), although others (e.g., Capretta, 1961; Wilcoxon, Dragoin, \& Kral, 1971) have found the opposite results. Our data suggest that, following aversion conditioning, aversive properties may transfer to new stimuli on the basis of novelty, although the stimuli may differ from the CS in class or modality. The magnitude, or perhaps the persistence, of the generalized aversion may then depend upon inherent characteristics of the CS and/or the new stimuli (e.g., their salience; see Franchina \& Dyer, 1985). The relative influences of novelty, stimulus modality, 
and salience in regulating food aversions awaits further research.

\section{REFERENCES}

Braveman, N. S. (1978). Preexposure to feeding-related stimuli reduces neophobia. Animal Learning \& Behavior, 6, 417-422.

BrAveman, N. S., \& JARVIS, P. S. (1978). Independence of neophobia and taste aversion learning. Animal Leaming \& Behavior, 6, 406-412.

Capretta, P. J. (1961). An experimental modification of food preferences in chicks. Journal of Comparative \& Physiological Psychology, 54, 238-242.

Clarke, J. C., Westbrook, R. F., Irwin, J. (1979). Potentiation instead of overshadowing in the pigeon. Behavioral \& Neural Biology, 25, 18-29.

DEESE, J., \& HuLSE, S. H. (1958). The psychology of learning. New York: McGraw-Hill.

Domjan, M. (1976). Determinants of the enhancement of flavor-water intake by prior exposure. Joumal of Experimental Psychology: Animal Behavior Processes, 2, 17-27.

DOMJAN, M. (1980). Ingestional aversion learning: Unique and general processes. In J. S. Rosenblatt, R. A. Hinde, C. Beer, \& M. C. Busnet (Eds.), Advances in the study of behavior (Vol. 11, pp. 275-336). New York: Academic Press.

Franchina, J. J., \& DYer, A. B. (1985). Aversion conditioning and enhanced neophobia: Role of test stimuli. Behavioral \& Neural Biology, 44, 122-131.

Franchina, J. J., \& Gilley, D. W. (1986). Effects of pretraining on conditioning-enhanced neophobia: Evidence for separable mechanisms of neophobia and aversion conditioning. Animal Learning \& Behavior, 14, 155-162.

Galef, B. G., JR., \& DalRy MPLE, A. J. (1981). Toxicosis-based aversions to visual cues in rats: A test of the Testa and Ternes hypothesis. Animal Learning \& Behavior. 9, 332-334.
GAlef, B. G., JR., \& OSBORne, B. (1978). Novel taste facilitation of the association of visual cues with toxicosis in rats. Journal of Comparative \& Physiological Psychology, 92, 907-916.

GASTON, K. E. (1977). An illness-induced aversion in domestic chicks: One trial learning with a long delay of reinforcement. Behavioral Biology, 20, 441-453.

Gillette, K., Martin, G. M., \& Bellingham, W. P. (1980). Differential use of food and water cues in the formation of conditioned aversions by domestic chicks (Gallus gallus). Journal of Experimental Psychology: Animal Behavior Processes, 6, 99-111.

KalAT, J. W. (1974). Taste salience depends on novelty, not concentration in taste aversion learning in the rat. Joumal of Comparative \& Physiological Psychology, 86, 47-50.

Miller, R. R., Holzman, A. D. (1981). Neophobias and conditioned taste aversions in rats following exposure to novel flavors. Animal Learning \& Behavior, 9, 89-100.

Mitchell, D., Kirschbaum, E. H., Perry, R. L. (1975). Effects of neophobia and habituation on the poison-induced avoidance of exteroceptive stimuli in the rat. Journal of Experimental Psychology: Animal Behavior Processes, 104, 47-55.

Mitchell, D., Winter, W., Moffitt, T. (1980). Cross-modality contrast: Exteroceptive context habituation enhances taste neophobia and conditioned taste aversions. Animal Learning \& Behavior, 8, 524-528.

WILCoxon, H. C. (1977). Long-delay learning of ingestive aversions in quail. In L. M. Barker, M. R. Best, \& M. Domjan (Eds.), Learning mechanisms in food selection (pp. 419-453). Waco, TX: Baylor University Press.

Wilcoxon, H. C., Dragoin, W. B., \& Kral, P. A. (1971). Illness induced aversions in rat and quail: Relative salience of visual and gustatory cues. Science, 171, 826-828.

(Manuscript received August 26, 1987; revision accepted for publication October $31,1988$. ) 